Reprod. Nutr. Dévelop., 1982, 22 (4), 651-660.

\title{
Electromagnetic measurements of duodenal digesta flow in cannulated sheep
}

\author{
C. PONCET, M. IVAN (1), M. LÉVEILLÉ
}

Laboratoire de la Digestion des Ruminants, I.N.R.A. Theix, 63110 Beaumont, France.

Summary. Studies of duodenal digesta flow were made in sheep implanted with an electromagnetic flowmeter probe on the ascending and transverse duodenum and in sheep equipped in the ascending duodenum with a ' $Y$ '-type or 'Ash'-type reentrant cannula or with a 'special simple' cannula. The flow of digesta was recorded between one week and 5 months after surgery. Patterns of the digesta flow through the individual systems of cannulation were compared with that of an implanted probe used as a reference. The order of similarity was Ash reentrant cannula $<Y$ reentrant cannula $<$ special simple cannula. The rate of digesta flow was similar for the probe, the Ash reentrant cannula with a oneway valve and the special simple cannula, but it was lower for the $Y$ reentrant cannula due to frequent oscillation of the digesta. It was concluded that accurate quantitative electromagnetic measurements of duodenal digesta flow can now be performed in sheep fitted with the Ash-type reentrant cannula equipped with a one-way valve.

\section{Introduction.}

Since the flow of digesta was first electromagnetically measured in sheep and goats (Singleton, 1961; Ridges and Singleton, 1962), the sensitivity of the electromagnetic flowmeters has been greatly improved and the transducers have been miniaturized. This miniaturization has made it possible to implant the transducers on the small intestine of animals (Bueno et al., 1975 ; Dardillat, 1977) or to insert them into intestinal reentrant cannulas (Poncet et al., 1976; Sissons and Smith, 1979) for the purpose of continuously recording digesta movements and taking quantitative measurements of digesta flow. Quantitative measurement is particularly important in studies of digestion and absorption in ruminant animals. In contrast to other techniques employing non-absorbable markers or the total collection of digesta from reentrant cannulas, the electromagnetic technique permits continuous measurement of the flow of digesta through the reentrant cannula for an extended period of time without any interruption in the flow. A highly sensitive electromagnetic flowmeter has been developed for this purpose (Léveillé et al., 1979).

(1) Visiting scientist from the (present address) Animal Research Centre, Agriculture Canada, Ottawa, Ontario, Canada KIA OC6 (Contribution No. 1029). 
It has been shown (Wenham and Wyburn, 1980) that the magnitude of deviations from the normal pattern of intestinal motility in cannulated sheep was dependent on the type of reentrant cannula used. However, the effects of different reentrant cannulas on the electromagnetically measured of duodenal digesta flow are not known. The present paper reports a study of the electromagnetic measurements of duodenal digesta flow in sheep equipped with a ' $Y$ '-type (Ivan and Johnston, 1981), an 'Ash'-type (Ash, 1962) or a 'special simple' cannula. The recordings of the duodenal digesta flow obtained with an implanted flowmeter probe were used as a reference.

\section{Material and methods.}

Fifteen Texel wethers, 7 to 18 months old and weighing 35 to $45 \mathrm{~kg}$, were maintained on a daily ration of $200-300 \mathrm{~g}$ of pelleted barley and $1.0-1.2 \mathrm{~kg}$ of good-quality hay. They were housed in individual pens and had continuous access to water and trace mineralized salt blocks. Four of the sheep 17 to 9 months old) were surgically implanted with an electromagnetic flowmeter probe (type 1603W, Nycotron, Dramen, Norway), two sheep on the ascending duodenum $15 \mathrm{~cm}$ after the pylorus and two sheep on the transverse duodenum immediately after the Sigmoid flexure. For the probe's electrodes to make proper contact with the intestinal wall, a $2-\mathrm{cm}$ long Dacron mesh was attached inside the probe by glue and sutures. The probe was then placed over the intestine and the two ends of the mesh which encircled the intestine were sutured to the intestinal wall. A cable connecting the probe to the flowmeter was exteriorized through a stab wound in the abdominal wall.

Five sheep (12 months old) were fitted with the $Y$-type reentrant cannula (Ivan and Johnston, 1981) and five (18 months old) with the Ash-type reentrant cannula (Ash, 1962). The cannulas were placed in the ascending duodenum 2 to $7 \mathrm{~cm}$ after the pylorus ; the distal cannula of the Ash-type reentrant cannulation system was placed in the transverse duodenum immediately after the Sigmoid flexure.

One sheep (12 months old) was fitted with a special simple cannula (fig. 1) in the ascending duodenum $6 \mathrm{~cm}$ after the pylorus. The cannula, moulded from PVC plastisol, consisted of a foot joined to a barrel with an external ring on the barrel's distal end and a perforated flange which encircled the barrel above the foot. Two plugs were used, one with an 11-mm I.D. tube and the other without the tube on the distal end. Both plugs fitted the inside of the cannula. In order to prevent an enlargement of the duodenal diameter under the cannula, a straight 5$\mathrm{cm}$ long arterial prosthesis (22 cml.D.) of woven Dacron (cat. no. 007070, USCl, Billerica, Mass. 01821, USA) was placed over the cannulated part of the duodenum ; the procedure was similar to that described by Ivan and Johnston (1981). The plug with the tube was kept inside the cannula for 2 weeks after surgery and for 3 days before each measurement of digesta flow. The plug without the tube was kept inside the cannula at all times, except during measurement. Due to an infection around the cannula, this sheep was killed 3 months after surgery. 


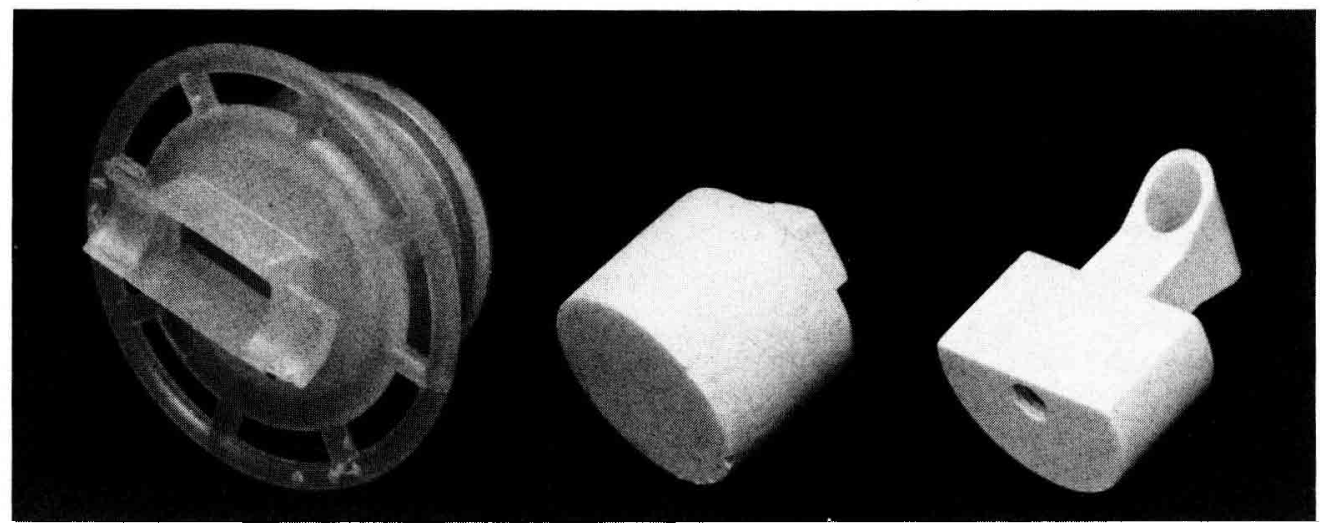

FIG. 1. - View of the special simple cannula and plugs.

The digesta flow was recorded between one week and 5 months after surgery by an electromagnetic flowmeter described previously (Poncet et al., 1977 ; Léveillé et al., 1979). Each recording lasted a minimum of 24 hours. The electromagnetic flowmeter transducer used with the Ash-type reentrant cannula was purchased from Nycotron, Dramen, Norway (type 1607), but those used with the $Y$-type reentrant cannula and the special simple cannula were constructed in this laboratory. The former transducer was fitted between the two barrels on the external part of the Ash-type reentrant cannula, while the latter two were inserted into the $Y$-type and the special simple cannulas by replacing the circular valve and the plug, respectively. Flow through the Ash-type reentrant cannula was recorded with and without a one-way valve inserted behind the transducer (Léveillé et al., 1979). The implanted probe was calibrated before surgery by attaching it to approximately $10 \mathrm{~cm}$ of duodenum obtained from a slaughtered sheep and then measuring the flow of known amounts of duodenal digesta passing through the segment. The flowmeter transducers used with the cannulas were calibrated in vitro before each recording by passing a known amount of duodenal digesta through the assembled cannulas, simulating an in vivo condition.

\section{Results.}

Implanted probe. - Recordings of the digesta flow through the probes implanted on the ascending and transverse duodena are shown in figure 2. Periods of regular flow were followed by oscillations and then by periods with no flow. The pattern of digesta flow in the ascending duodenum showed welldefined peaks, each representing an individual bolus of digesta propelled along the duodenum. The volume of the boluses was between 5 and $19 \mathrm{ml}$. There was also an occasional back-flow of $2-4 \mathrm{ml}$ of digesta. Some back-flows appeared immediately after the passage of a bolus, but others were isolated and appeared between two propelled boluses. The mean hourly frequency of the passage of boluses through the ascending duodenum was 39.1 (table 1). The pattern of digesta flow along the transverse duodenum (fig. 2) was much less uniform than 


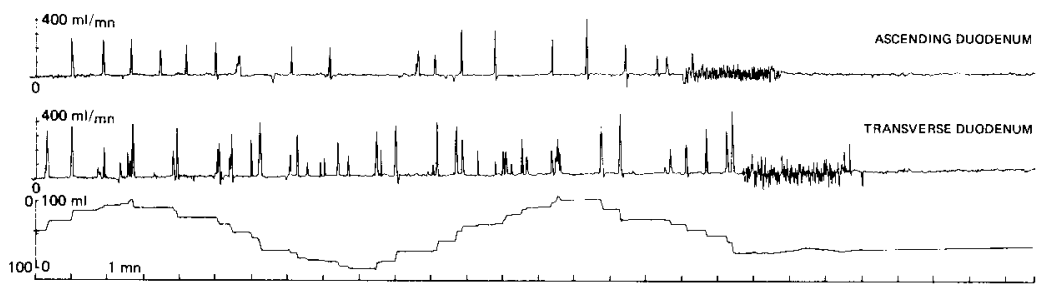

FIG. 2. - Pattern of digesta flow in the ascending and transverse duodena measured with an implanted flowmeter probe. The flow in the transverse duodenum is presented with the cumulative quantitative electronic integration of $100-\mathrm{ml}$ fractions with a double origin.

that along the ascending duodenum. The majority of boluses passing the transverse duodenum appeared as a group of variable quantities of digesta, whereas others appeared as simple well-defined peaks similar to those in the ascending duodenum. In contrast to the ascending duodenum, the back-flow of digesta in the transverse duodenum appeared mainly as a reflux after the passage of some boluses, and isolated back-flows were almost non-existent. Generally, changes in digesta flow were observed as recurrent cycles in which the period without the net flow of digesta lasted for 10-15 min in both the ascending and the transverse duodena and the period of digesta flow lasted an average of $92 \mathrm{~min}$. Mean hourly digesta flow in the transverse duodenum amounted to $784 \mathrm{ml}$ with a frequency of 53.3 boluses/h (table 1).

\section{TABLE 1}

Pattern of duodenal digesta flow (mean of means \pm SD) in sheep with different surgical cannulation systems

\begin{tabular}{lccc}
\hline \multicolumn{1}{c}{ Type of system } & $\begin{array}{c}\text { Number } \\
\text { of animals }\end{array}$ & $\begin{array}{c}\text { Digesta flow } \\
\mathrm{ml} / \mathrm{h}\end{array}$ & $\begin{array}{c}\text { Number of } \\
\text { boluses } / \mathrm{h}\end{array}$ \\
\hline $\begin{array}{l}\text { Implanted probe } \\
\text { (ascending duodenum) } \\
\text { (transverse duodenum) }\end{array}$ & 2 & $\mathrm{ND}$ & $39.1 \pm 3.4$ \\
$\begin{array}{l}\text { Y-type reentrant cannula } \\
\text { (ascending duodenum) }\end{array}$ & 2 & $784 \pm 74$ & $53.3 \pm 10.0$ \\
$\begin{array}{l}\text { Ash-type reentrant cannula with one-way valve } \\
\text { (ascending duodenum) }\end{array}$ & 5 & $527 \pm 79$ & $39.7 \pm 4.0$ \\
$\begin{array}{l}\text { Special simple cannula } \\
\text { (ascending duodenum) }\end{array}$ & 5 & $740 \pm 129$ & $35.0 \pm 8.8$ \\
\hline
\end{tabular}

$\mathrm{ND}=$ Not determined

Y-type reentrant cannula. - The pattern of digesta flow in the ascending duodenum varied among the individual sheep equipped with the $Y$-type reentrant cannula. Generally, the pattern of digesta flow during the period 1-2 weeks after surgery was similar to that of the digesta flow shown in fig. 3 . It consisted of relatively small boluses propelled through the cannula in groups of 3 to 7 . The 


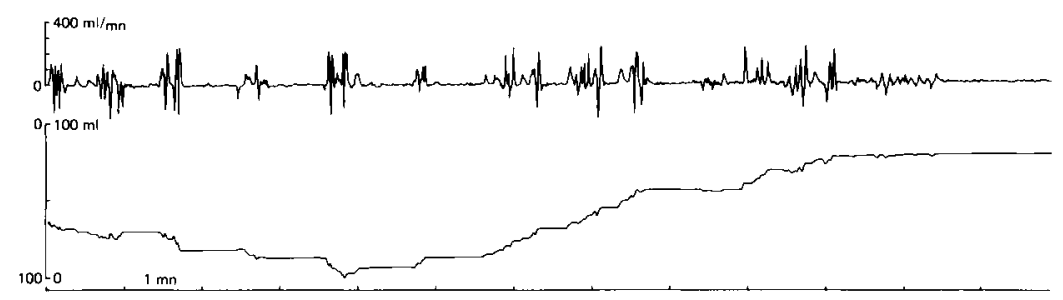

FIG. 3. - Pattern of digesta flow and quantitative electronic integration at 1-2 weeks after surgical insertion of the $Y$-type reentrant cannula into the ascending duodenum of sheep.

boluses within each group were separated by a relatively large reflux of up to $5 \mathrm{ml}$ of digesta. The rate of positive flow of individual boluses only reached about $250 \mathrm{ml} / \mathrm{min}$ and was frequently followed by approximately the same magnitude of reflux. The volume of the net flow of the bolus groups ranged between 0 and $19 \mathrm{ml}$, and the mean frequency of their passage through the cannula was $39.7 / \mathrm{h}$. Recordings made about 4 weeks after surgery (fig. 4A) showed a general improvement in the pattern of digesta flow. The bolus groupings seen at 1-2 weeks after surgery (fig. 3) had mostly disappeared, and the pattern of digesta flow (fig. 4A) consisted of well-defined boluses recorded as simple peaks with magnitudes of up to about $500 \mathrm{ml} / \mathrm{min}$. However, the reflux and back-flow of digesta did not disappear though they were relatively smaller and less frequent. The volume of the net flow of individual boluses ranged between 3 and $17 \mathrm{ml}$. The mean frequency of the passage of individual boluses through the cannula was $48.6 / \mathrm{h}$. Using the electromagnetic technique, the flow was more accurately quantified by the recordings at 4 weeks after surgery than by those at 1-2 weeks after surgery. However, accuracy was even better in some sheep at 6 weeks or more after surgery. At that time, the pattern of digesta flow (fig. 4B) consisted of well-

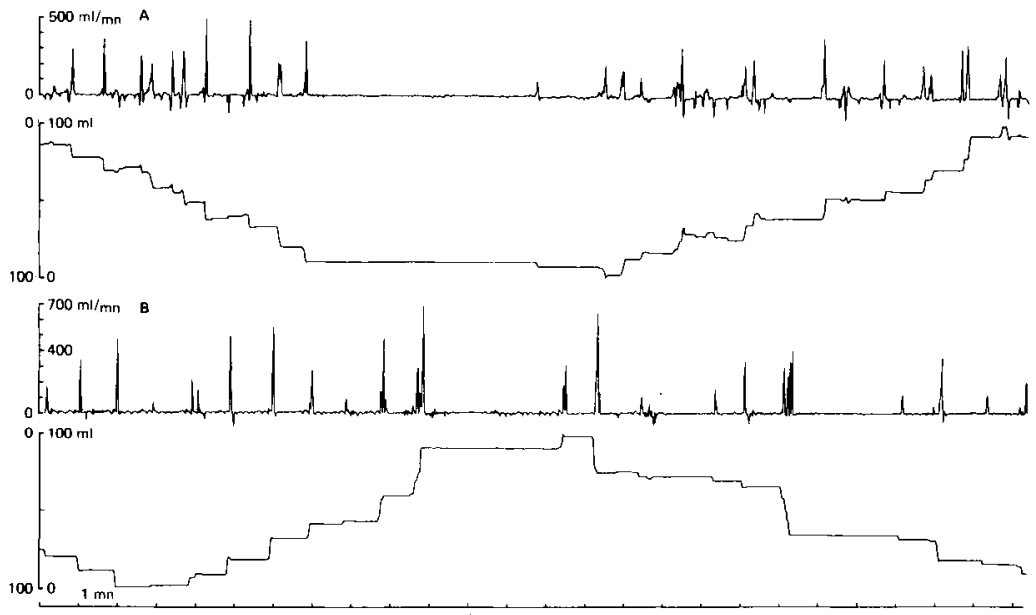

FIG. 4. - Pattern of digesta flow and quantitative electronic integration at 4 (A) and 6 (B) weeks after surgical insertion of the Y-type reentrant cannula into the ascending duodenum of sheep. 
defined boluses recorded mostly as single peaks with a magnitude of up to approximately $680 \mathrm{ml} / \mathrm{min}$. Although there were relatively small refluxes after the individual boluses had passed through the cannula, there were no apparent individual back-flows of digesta. The mean frequency of the passage of individual boluses through the cannula was $41.4 / \mathrm{h}$; their mean volume, ranging between 3 and $30 \mathrm{ml}$, was $12 \mathrm{ml}$.

In one sheep with the cannula placed about $2 \mathrm{~cm}$ after the pylorus, the flow pattern did not change with time after surgery, remaining similar to that shown in figure 3 . Similarly, in one sheep with the cannula placed $7 \mathrm{~cm}$ after the pylorus, a flow pattern of digesta resembling that in fig. 4B appeared at 1-2 weeks after surgery and continued almost unchanged thereafter. The remaining 3 sheep with the Y-type cannula placed $4-5 \mathrm{~cm}$ after the pylorus showed a general improvement in the flow pattern with time after surgery, as mentioned above.

Ash-type reentrant cannula. - The pattern of digesta flow through the Ashtype cannula without the one-way valve (fig. 5A) consisted of small and large boluses, each associated with a large reflux followed by a relatively large and continuous oscillation. The amplitude of the oscillation increased greatly just before the passage of each bolus. Because of large oscillations between boluses, the flow of digesta through the cannula could not be quantified by the electromagnetic technique. The amplitudes of individual peaks representing positive flow or reflux reached 750 and $360 \mathrm{ml} / \mathrm{min}$, respectively. The frequency of the passage of boluses through the cannula was 40.2 with a mean bolus volume of $17 \mathrm{ml}$. The pattern of digesta flow in these sheep did not change with time after surgery. The incorporation of a one-way valve after the flowmeter transducer eliminated the oscillation of digesta in the cannula and allowed

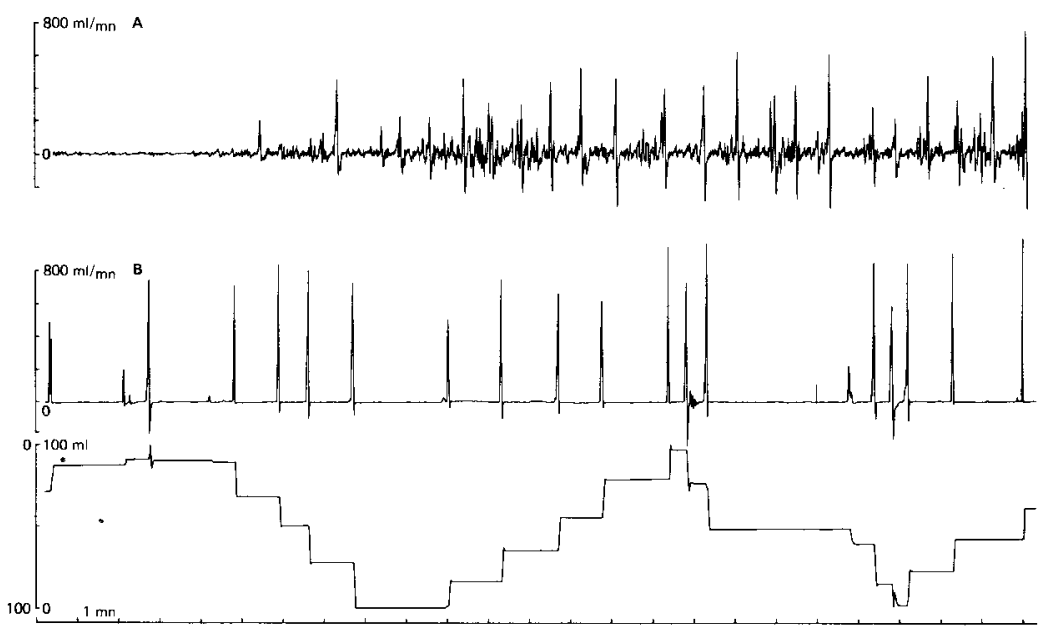

FIG. 5. - Pattern of digesta flow at 1-6 weeks after surgical insertion of the Ash-type reentrant cannula into the ascending duodenum of sheep. The measurements were made without (A) or with (B) the one-way valve attached to the external part of the cannula. The flow in $B$ is presented with the cumulative quantitative electronic integration of $100-\mathrm{ml}$ fractions with a double origin. 
accurate quantification of the digesta flow by the electromagnetic technique (fig. 5B). The pattern of digesta flow consisted of individual boluses with amplitudes of up to about $850 \mathrm{ml} / \mathrm{min}$ which were sometimes followed by a small reflux. The mean frequency of the passage of boluses through the cannula was $35.0 / \mathrm{h}$ (table 1) ; mean bolus volume, ranging between 12 and $32 \mathrm{ml}$, was $22 \mathrm{ml}$.

Special simple cannula. - The pattern of digesta flow in the ascending duodenum 5 days after surgery (fig. 6A) consisted of relatively small boluses grouped in series of 2 to 4 . Although there was no apparent back-flow of digesta, there was some reflux after the passage of larger boluses. The pattern of digesta flow, greatly improved within one month after surgery (fig. 6B), consisted of welldefined individual boluses passing the cannula without any apparent back-flow. The amplitude of the peaks was approximately between 250 and $550 \mathrm{ml} / \mathrm{min}$. The mean frequency of bolus passage was $39.9 / \mathrm{h}$ (table 1 ) ; mean bolus volume, ranging between 10 and $43 \mathrm{ml}$, was $20 \mathrm{ml}$.

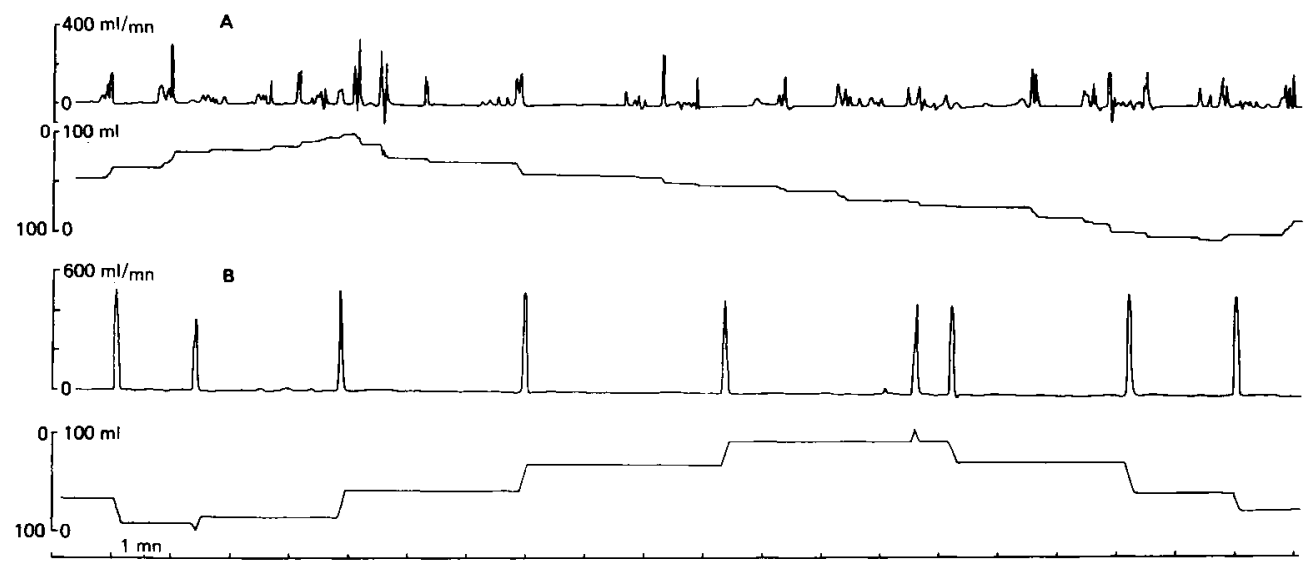

FIG. 6. - Pattern of digesta flow and cumulative quantitative electronic integration of 100-m/ fractions with a double origin at 5 (A) and 30 (B) days after surgical insertion of the special simple cannula into the ascending duodenum of sheep.

\section{Discussion.}

The propulsive nature of gastrointestinal motility in sheep has been found to be correlated with a migrating myoelectric complex comprised of a phase of irregular spiking activity (ISA), followed by a phase of regular spiking activity (RSA) and then a quiescent period (OP) (Ruckebusch, 1970). Only ISA has been associated with the intestinal flow of digesta (Ruckebusch and Bueno, 1977). Using electromyography (Ruckebusch, 1970), we found that the probe implanted on the ascending duodenum had an apparent slight effect on the uniformity of the spiking electrical activity at the distal antrum but did not affect the electrical activity at the duodenum (Poncet and Ivan, unpublished). In the present study, the pattern of digesta flow in the ascending and transverse duodena of sheep 
equipped with the probe (fig. 2) consisted of a well-defined net flow of digesta which corresponded to ISA, followed by an oscillation corresponding to RSA and then by a period of no flow which conformed to the QP. The oscillation during the RSA was caused by the continuous presence of a small quantity of digesta in the region of the probe. However, the oscillation did not produce any net flow of digesta. Although in the ascending duodenum there was some back-flow and reflux of digesta during ISA (which seems to be a normal phenomenon) (Wenham and Wyburn, 1980), there was distinct propagation of well-separated individual boluses. The pattern of digesta flow obtained with the probe was used as a reference for comparisons of digesta flow in the ascending duodenum of cannulated sheep. However, due to the low sensitivity of the commerciallyproduced probes, it was difficult to stabilize the baseline of the probe on the ascending duodenum and, therefore, the digesta flow in the ascending duodenum was not always quantified accurately. For this reason, the rate of digesta flow in that duodenum was not calculated but the rate in the transverse duodenum was assumed to be about the same as that in the ascending duodenum, even though some contribution from the bile and pancreatic secretions was to be expected.

A comparison of the patterns of digesta flow in the different surgical systems in sheep clearly showed that the order of similarity to the reference pattern was Ash reentrant cannula $<Y$ reentrant cannula $<$ special simple cannula. In fact, the pattern of flow through the Ash cannula without the one-way valve was such that the digesta flow could not be quantitatively measured with the electromagnetic technique. However, when the valve was incorporated into the system, the quantitative flow rate was similar to the reference flow rate; the rate of flow obtained with the special simple cannula was also similar to the reference flow rate. Although the pattern of digesta flow in the majority of sheep with $Y$ cannulas resembled that of the reference sheep, generally later after surgery, the rate of digesta flow was much lower than in the other cannulated sheep (table 1). It is interesting to note that the mean number of boluses per hour was almost identical to that in the ascending duodenum of the reference sheep but that the mean volume of the boluses was quite low, showing that the quantitative electromagnetic measurement of digesta flow through the Y-type cannula was not accurate. This inaccuracy was probably due to frequent oscillations of the digesta in the cannula, resulting in a shift of the baseline in the flowmeter and an underestimation of the volume of the individual boluses. A similar problem was also encountered in sheep equipped with the probe on the ascending duodenum ; the shifting of the baseline in these sheep was even greater than in those with $Y$ cannulas. Since the one-way valve cannot be incorporated into the Y-type reentrant cannula and the presently available flowmeter transducers are not sensitive enough to properly integrate the oscillations, we cannot yet take quantitative measurements of digesta flow in the Y-type cannula.

The cannulas (proximal end of the intestinal tube) in the sheep fitted with the Y-type reentrant system were situated 2 to $7 \mathrm{~cm}$ from the pylorus. We observed that the pattern of digesta movement in those sheep having the cannula 5 to $7 \mathrm{~cm}$ from the pylorus was similar to that of the reference. However, when the cannula was nearer to the pylorus, the pattern differed from the reference and 
remained unchanged (sheep with the cannula $2 \mathrm{~cm}$ from the pylorus) or was improved (sheep with the cannula 4 to $5 \mathrm{~cm}$ from the pylorus) with time after surgery. This observation indicated that for strong contraction, and hence for efficient propulsion of digesta into the transverse duodenum, the proximal part of the duodenal bulb should not be in contact with the cannula. When the cannula was placed close to the pylorus, parts of the insufficiently-propelled boluses refluxed to the bulb at the end of each large contraction, initiating a new contraction which resulted in a small gush. The cycle of flux and reflux usually occurred 2 or 3 times until a sufficient volume of digesta had accumulated and was transferred aborally. The evolution towards the normal pattern of digesta flow in sheep with the cannula placed $4-5 \mathrm{~cm}$ after the pylorus was probably related to stronger than normal contractions of the duodenal bulb which were observed to commence between 2 and 4 weeks after surgery.

In sheep equipped with the Ash-type cannulas, modifications in the pattern of digesta flow were mainly due to the length (approximately $18 \mathrm{~cm}$ ) of the external tubing of the cannulation system. After each contraction of the duodenal bulb, the digesta remaining in the tubing refluxed back into the bulb. We noted that the reflux tended to increase with time after surgery, probably due to the larger size of the duodenal bulb. The oscillations recorded in these sheep between individual boluses occurred at the same frequency as that of breathing and were therefore produced by variation in abdominal pressure.

Although our results clearly show qualitative modifications in the pattern of duodenal flow in sheep fitted with a reentrant cannula, they fail to indicate any significant quantitative modification in the flow of digesta. This is in agreement with other experiments in which cannulation did not affect the retention times in the gastrointestinal tract of solid and liquid-phase markers (Grovum and Williams, 1973 ; MacRae and Wilson, 1977). It is therefore evident that gastroduodenal propulsive activity undergoes a period of adaptation after cannulation. The adaptation period in sheep equipped with the Y-type cannula is probably slightly longer than in those fitted the Ash-type cannula. However, if the $Y$-type cannula is placed far enough from the pylorus $(4 \mathrm{~cm}$ or more), it is our opinion that gut motility would reach equilibrium by 4 weeks after surgery and the sheep could then be used for experimental work.

The results with the special simple cannula are very encouraging but far from conclusive. Only one sheep was used in the present experiment, and it had to be killed 3 months after surgery due to an infection. There was also an indication that the intestine might eventually grow through and detach from the arterial prosthesis, making it impossible to measure the flow of digesta. Sheep with this type of cannula would therefore be useful for electromagnetic measurements of digesta flow for only a limited period of time, perhaps for $\mathbf{4}$ months after surgery. More investigation, however, is needed before any conclusions can be drawn as to the usefulness of this type of cannulation. Meanwhile, accurate quantitative electromagnetic measurements of duodenal digesta flow can be performed in sheep fitted with the Ash-type reentrant cannula equipped with a one-way valve, as previously described by Léveillé et al. (1979). 
Résumé. La mesure du débit du contenu digestif duodénal a été effectuée sur des moutons munis d'un capteur électromagnétique implanté sur la partie ascendante ou sur la partie transverse du duodénum, et sur des moutons munis d'une canule réentrante en " $Y$ ", ou d'une canule réentrante d'ASH, ou d'une canule simple spéciale, placée dans la partie ascendante du duodénum. Les mesures de débit duodénal ont commencé 8 jours après l'opération et ont été poursuivies pendant une durée variable (5 mois au maximum). Les enregistrements obtenus avec chaque type de canule ont été comparés à ceux fournis par les capteurs implantés qui ont servi de référence. Par ordre de similitude croissante avec ces derniers enregistrements, les différents types de canules se sont classés de la façon suivante : canule réentrante d'Ash < canule réentrante en " $Y$ " < canule simple spéciale. Le débit horaire des digesta a été peu différent entre les animaux munis d'une sonde implantée, ou d'une canule réentrante d'Ash équipée d'un dispositif anti-retour ou de la canule simple spéciale, mais il a été plus faible avec les animaux munis de la canule en " $Y$ " à cause de fréquentes oscillations du contenu digestif dans la canule. Actuellement, il est donc possible d'effectuer des mesures précises du débit duodénal sur des moutons porteurs de canules réentrantes d'Ash.

\section{References}

ASH R. W., 1962. Gastro-intestinal reentrant cannulae for studies of digestion in sheep. Anim. Prod., 4, 309-312.

BUENO L., FIORAMONT J., RUCKBUSCH Y., 1975. Rate of flow of digesta and electrical activity of the small intestine in dogs and sheep. J. Physiol., 249, 69-85.

DARDILLAT C., 1977. Analyse électromyographique et débitmétrique du transit alimentaire chez le veau nouveau-né. J. Physiol., Paris, 73, 925-944.

GROVUM W. L., WILLIAMS V. J., 1973. Rate of passage of digesta in sheep. 4. Passage of marker through the alimentary tract and the biological relevance of rate-constants derived from changes in concentration of marker in feces. Br. J. Nutr., 30, 313-329.

IVAN M., JOHNSTON D. W., 1981. Reentrant cannulation of the small intestine in sheep : cannula and surgical method. J. anim. Sci, 52, 849-856.

LÉVEILLÉ M., PONCET C., DARDILLAT C., 1979. Characteristics of an electromagnetic flowmeter especially built to measure intestinal flow in sheep. Ann. Rech. vét., 10, 497-499.

MacRAE J. C., WILSON S., 1977. The effects of various forms of gastrointestinal cannulation on digestive measurements in sheep. Br. J. Nutr., 38, 65-71.

PONCET C., DIMOVA E., DARDILLAT C., THIVEND P., 1976. Measurement of flow of intestinal contents in sheep by an electromagnetic method. Proc. Nutr. Soc., 35. 107A.

PONCET C., DIMOVA E., LÉVEILLÉ M., DARDILlaT C., 1977. Mise au point d'une méthode d'enregistrement chronique du débit duodénal chez le mouton : exemple d'application. Ann. Biol. anim. Bioch. Biophys., 17, 515-522.

RIDGES A. P., SINGLETON A. G., 1962. Some quantitative aspects of digestion in goats. J. Physiol., $161,1-9$.

RUCKBUSCH Y., 1970. The electrical activity of the digestive tract of the sheep as an indication of the mechanical events in various regions. J. Physiol., 210, 857-882.

RUCKEBUSCH Y., BUENO L., 1977. Origin of migrating myoelectric complex in sheep. Am. J. Physiol., 233, E483-E487.

SINGLETON A. G., 1961. The electromagnetic measurement of the flow of digesta through the duodenum of the goat and the sheep. J. Physiol., 155, 134-147.

SISSONS J. W., SMITH R. H., 1979. Digesta movement and gut motility in the preruminant calf. Ann. Rech. vét., 10, 176-178.

WENHAM G., WYBURN R. S., 1980. A radiological investigation of the effects of cannulation on intestinal motility and digesta flow in sheep. J. agric. Sci., Camb., 95, 539-546. 